A. M. Croom | Integrative Psychological and Behavioral Science 48 (2014) 18-47

http://dx.doi.org/10.1007/s12124-013-9249-8

\title{
Vindicating virtue: A critical analysis of the situationist challenge against Aristotelian moral psychology
}

\author{
Adam M. Croom \\ University of Pennsylvania \\ (C) Springer Science + Business Media, LLC 2013
}

\begin{abstract}
This article provides a critical analysis of the situationist challenge against Aristotelian moral psychology. It first outlines the details and results from 4 paradigmatic studies in psychology that situationists have heavily drawn upon in their critique of the Aristotelian conception of virtuous characteristics, including studies conducted by Hartshorne and May (1928), Darley and Batson (1973), Isen and Levin (1972), and Milgram (1963). It then presents 10 problems with the way situationists have used these studies to challenge Aristotelian moral psychology. After challenging the situationists on these grounds, the article then proceeds to challenge the situationist presentation of the Aristotelian conception, showing that situationists have provided an oversimplified caricature of it that goes against the grain of much Aristotelian text. In evaluating the situationist challenge against the actual results from empirical research as well as primary Aristotelian text, it will be shown that the situationist debate has advanced both an extreme, untenable view about the nature of characteristics and situations, as well as an inaccurate presentation of the Aristotelian view.
\end{abstract}

Keywords: Aristotle; character; development; habits; moral psychology; perceptual learning; personality; situationist challenge; virtue ethics 
A. M. Croom | Integrative Psychological and Behavioral Science 48 (2014) 18-47

http://dx.doi.org/10.1007/s12124-013-9249-8

Man's character is his fate. - Heraclitus ${ }^{1}$

there is no empirical basis for the existence of character traits. - Gilbert Harman ${ }^{2}$

\section{Introduction}

It has become fashionable among contemporary philosophers and psychologists to critique Aristotelian moral psychology on the basis of recent empirical work from social psychology. For example, several scholars have claimed that recent empirical research on the role of character-based and situation-based influences on human behavior have demonstrated that situations rather than characteristics ${ }^{3}$ determine human behavior (Doris, 1998; Harman, 1999; Harman, 2000). ${ }^{4}$ This challenge against Aristotelians has become well known in the literature as the situationist challenge, and as Prinz (2009) points out in a recent article published in The Journal of Ethics, situationists have primarily drawn upon results from four paradigmatic studies in social and personality psychology which have become representative of the situationist challenge (see Prinz, 2009, p. 119). These four empirical studies include those conducted by Hartshorne and May (1928), Darley and Batson (1973), Isen and Levin (1972), and Milgram (1963). Each of these studies proposes to seriously challenge the plausibility of Aristotelian moral psychology by calling into question the plausibility of character traits as such, for if there are no characteristics then there are no characteristics that are virtuous either.

The aim of this article is to raise serious doubts about the strength of the situationist challenge against Aristotelian moral psychology by presenting 10 problems with the situationist use of the aforementioned empirical results as well as calling into question the accuracy of their presentation of the Aristotelian conception of virtuous characteristics. The article will proceed to do this as follows: Section 2 reviews the three theses situationists ascribe to Aristotelians, including the (A1) stability, (A2) robustness, and (A3) evaluative consistency or integrity theses, as well as the three theses situationists claim to hold themselves, including the (S1) instability, (S2) impotence, and (S3)

${ }^{1}$ Quoted from fragment 121 in Heraclitus (2001) Fragments, B. Haxton (trans.). New York: Penguin Books. ${ }^{2}$ Quoted from p. 316 in Harman (1999) Moral philosophy meets social psychology: Virtue ethics and the fundamental attribution error. Proceedings of the Aristotelian Society, 99, 315-331.

${ }_{3}^{3}$ Although situationists often use the term character traits (Doris, 1998; Harman, 1999; Prinz, 2009), Aristotle himself used the term characteristics in discussing the virtues. For instance: "some of the virtues are intellectual, others moral: wisdom, comprehension [or understanding], and prudence being intellectual, liberality and moderation being moral [...] we say that of the characteristics, the praiseworthy ones are virtues" (NE 1103a510). For the most part, my choice of terms will agree with Aristotle's, for it is often thought that some traits are innate (see for instance Prinz, 2008; Schmitt, Realo, Voracek, \& Allik, 2008) but characteristics are certainly not innate on the Aristotelian conception (see for instance NE 1103a15-20). Indeed, this is one way that Aristotle seems to distinguish characteristics from capacities, since capacities are "present in us by nature" while virtues and vices are not (see for instance NE 1103a25-1103b). For Aristotle, examples of capacities would include seeing and hearing whereas examples of characteristics would include justice and courage (NE 1103a25-1103b). ${ }^{4}$ For instance, in his aptly titled article "The nonexistence of character traits," Harman (2000) claims that, "We need to convince people to look at situational factors and to stop trying to explain things in terms of character traits. We need to abandon all talk of virtue and character" (p. 224). 
A. M. Croom | Integrative Psychological and Behavioral Science 48 (2014) 18-47

http://dx.doi.org/10.1007/s12124-013-9249-8

evaluative inconsistency or fragmentation of character theses. In sections 3, 4, 5, and 6 we review the details and results of the studies conducted by Hartshorne and May (1928), Darley and Batson (1973), Isen and Levin (1972), and Milgram (1963), respectively, and how the situationist uses each of these results against Aristotelians. Section 7 reconsiders the Hartshorne and May (1928) study and presented 3 problems with the situationist use of it against Aristotelians, section 8 reconsiders the Darley and Batson (1973) study and presented 4 problems with the situationist use of it against Aristotelians, section 9 reconsiders the Isen and Levin (1972) study and presents 1 major problem with the situationist use of it against Aristotelians, and section 10 reconsiders the Milgram (1963) study and presents 2 problems with the situationist use of it against Aristotelians. Next, in section 11, it is argued that situationists have also advanced inaccurate characterizations of the Aristotelian conception of virtuous characteristics, while section 12 concludes.

\section{Aristotelian and situationist views on characteristic and situational influences on behavior}

Aristotelians, situationists have claimed, are committed to at least the following three theses regarding characteristics: (A1) the stability of character thesis, which holds that behavioral variation is due to different characteristics rather than different situations (Doris, 1998, p. 515; see also Harman, 1999, p. 316-317, 319, 329; Athanassoulis, 2000, p. 215; Prinz, 2009, p. 119), (A2) the robustness of character thesis, which holds that characteristics resist contrary situational pressures (Doris, 1998, p. 506; see also Harman, 1999, p. 318; Harman, 2000, p. 224; Prinz, 2009, p. 119), and (A3) the evaluative consistency or integrity of character thesis, which holds that the possession of any virtuous characteristic is highly correlated with the possession of other virtuous characteristics (Doris, 1998, p. 506; Prinz, 2009, p. 119). The situationist claim that Aristotelians are committed to these three theses is purportedly supported by textual evidence. For instance, in support of (A1) Doris (1998) cites Aristotle from Nicomachean Ethics (1105b1) and suggests that here Aristotle is claiming that for an action to count as virtuous "it must be determined by the appropriately developed character of the agent" (see Doris, 1998, p. 515). In support of (A2) Doris (1998) cites Aristotle from Nicomachean Ethics (1105b1) and Categories (8b25-9a9) and suggests that here Aristotle is claiming that good character is "firm and unchangeable" and that the virtues are "permanent and hard to change" (see Doris, 1998, p. 506; see also Merritt, 2009, p. 23). In support of (A3) Doris (1998) cites Aristotle from Nicomachean Ethics (1144b30-1145a2) and suggests that here Aristotle is claiming that "possession of one particular virtue entails possession of all the virtues" (see Doris, 1998, p. 506 and footnote 11 on p. 521). ${ }^{5}$

${ }^{5}$ Note also that Doris (1998) presents Aristotle as holding an "inventory of twelve virtues of character and eight intellectual virtues" (p. 508), but this is incorrect. For in Nicomachean Ethics Aristotle discusses 11 virtues 
A. M. Croom | Integrative Psychological and Behavioral Science 48 (2014) 18-47

http://dx.doi.org/10.1007/s12124-013-9249-8

Situationists have made it clear that, in contrast with Aristotelians, they are committed to at least the following three theses regarding characteristics: (S1) the instability of character thesis, which holds that behavioral variation is due to different situations rather than different characteristics (Doris, 1998, p. 507; Harman, 2000, p. 224), (S2) the impotence of character thesis, which holds that characteristics are not resistant to contrary situational pressures (Doris, 1998, p. 507-508), and (S3) the evaluative inconsistency or fragmentation of character thesis, which holds that the possession of any virtuous characteristic is not highly correlated with the possession of other virtuous characteristics (Doris, 1998, p. 509). For instance, in explicating (S1) Doris (1998) claims that "Behavioral variation across a population owes more to situational differences than dispositional differences among persons" and that "we are safest predicting, for a particular situation, that a person will behave pretty much as most others would” (p. 507). In explicating (S2) Doris (1998) claims that "behavior may vary quite radically when compared with that expected on the postulation of a given trait" (p. 508) since "Whatever behavioral reliability we do observe may be readily shortcircuited by situational variation” (p. 507). In explicating (S3) Doris (1998) claims that people possess “evaluatively fragmented trait-associations rather than evaluatively integrated ones" (p. 509).

Situationists have argued against the viability of Aristotelian moral psychology on the grounds that empirical evidence from recent studies in social and personality psychology purportedly support theses (S1)-(S3) but not theses (A1)-(A3). This challenge by situationists against Aristotelians has become well known in the literature as the situationist challenge, and as Prinz (2009) points out in a recent article published in The Journal of Ethics, situationists have primarily drawn upon results from four paradigmatic studies in social and personality psychology which have become representative of the situationist challenge. These four empirical studies include those conducted by Hartshorne and May (1928), Darley and Batson (1973), Isen and Levin (1972), and Milgram (1963). According to situationists, the results from these studies demonstrably undermine the plausibility of the Aristotelian conception of virtuous characteristics.

Roughly, the situationist strategy is to use empirical results from the four aforementioned studies to undermine the plausibility of characteristics as such, and in so doing also undermining the plausibility of characteristics that are virtuous, since virtuous characteristics constitute only a subset of all characteristics. So in order to assess the true merit of the situationist challenge against

of character (i.e., courage (book 3 chapter 9), moderation (book 3 chapter 10), liberality (book 4 chapter 1), magnificence (book 4 chapter 2), greatness of soul (book 4 chapter 3), ambition (book 4 chapter 4), gentleness (book 4 chapter 5), friendliness (book 4 chapter 6), truthfulness (book 4 chapter 7), wittiness or tact (book 4 chapter 8), and justice (book 5 chapter 1)) as well as 5 virtues of intellect (i.e., science (book 6 chapter 3), art (book 6 chapter 4), prudence (book 6 chapter 5), understanding (book 6 chapter 6), and wisdom (book 6 chapter 7). Regarding Aristotle's 11 virtues of character see also Aquinas, 1993, p. 174-351. Regarding Aristotle's 5 virtues of intellect see NE 1139b14-18; also Aquinas, 1993, p. 364-395; Kraut, 2012, section 6. 
A. M. Croom | Integrative Psychological and Behavioral Science 48 (2014) 18-47

http://dx.doi.org/10.1007/s12124-013-9249-8

Aristotelian moral psychology, it is important to first briefly review the details and results of the four paradigmatic empirical studies that have been used to support the situationist challenge.

\section{Study 1: Hartshorne and May (1928)}

First, let us consider the empirical study conducted by Hartshorne and May (1928). In this study the experimenters used 33 different behavioral ("service") tests on 10,865 subjects to assess their level of altruism, self-control, and honesty across different situational contexts. These different contexts included the classroom, at home, at play, and during athletics. Ratings of the subject's reputations with their classmates and teachers were taken in each of these contexts, and then the experimenters inter-correlated the subject's scores on these tests to determine whether their behavior could be generalized across all situations or were instead specific to certain situations. In other words, the experimenters reasoned that subject's behavior could be generalized across situations if these correlations were found to be high, but would have to be considered more situation-specific if these correlations were found to be low or non-existent. Subjects in this study consisted of children between 8 and 16 years of age (mostly between 5th and 8 th grade) and came from 23 communities across the United States.

The results from this study were as follows: The experimenters found relatively low intercorrelations with an average of approximately +0.20 between any two measures for altruism, honesty, and self-control (e.g., +0.23 for altruism). In other words, the experimenters found only a relatively low average of approximately +0.20 between any one behavioral test and any another behavioral test used to measure for altruism, honesty, and self-control. Situationists argue that the results from this study by Hartshorne and May (1928) offers damaging empirical evidence against the viability of the Aristotelian conception of virtuous characteristics. For example, Prinz (2009) claims that this study challenges Aristotelians on the grounds that it "shows that individuals behave in different ways across contexts in which they should behave similarly if they were acting under the influence of global character traits" and that "a person who doesn't steal may nevertheless cheat, which undermines the application of broad labels such as "honest" or "dishonest"” (p. 119-120).

\section{Study 2: Darley and Batson (1973)}

Next, let us consider the empirical study conducted by Darley and Batson (1973). In this study the experimenters began experimental procedures with subjects in one building and then instructed the subjects to report to another building to give a talk to others on some topic specified by the experimenter (the topic depended on whether the subject was in the talk-relevant or helping- 
A. M. Croom | Integrative Psychological and Behavioral Science 48 (2014) 18-47

http://dx.doi.org/10.1007/s12124-013-9249-8

relevant condition; see below). While each subject walked from one building to the next, they would pass a man slumped over in an alleyway with his head down, eyes closed, coughing and groaning.

The dependent variable in this study was whether and how the subject helped the slumped over man in the alleyway. There were two independent variables. The first independent variable was whether the subjects were in the task-relevant condition or in the helping-relevant condition. Subjects in the task-relevant condition were instructed to give a talk on the jobs in which seminary students would be most effective. Subjects in the helping-relevant condition were instructed to give a talk on the parable of the Good Samaritan. The second independent variable was whether the subjects were in the low-hurry condition, the intermediate-hurry condition, or the high-hurry condition. Subjects in the low-hurry condition were told, "It'll be a few minutes before they're ready for you, but you might as well head on over. If you have to wait over there, it shouldn't be long." Subjects in the intermediate-hurry condition were told, "The assistant is ready for you, so please go right over." Subjects in the high-hurry condition were told, "Oh, you're late. They were expecting you a few minutes ago. We'd better get moving. The assistant should be waiting for you so you'd better hurry. It shouldn't take but just a minute" (see Darley \& Batson, 1973, p. 103-104). Subjects consisted of 47 students at Princeton Theological Seminary.

The results from this study were as follows: 7 of the 47 subjects had their data excluded from the final analyses. 3 of the 7 were excluded due to contamination of the experimental procedures and 4 of the 7 were excluded due to their suspicion of the experimental situation. Data from the remaining 40 subjects served as the basis for analyses, and the experimenters found that 16 of the 40 subjects ( $40 \%$ ) offered some form of direct or indirect aid to the victim whereas 24 of the 40 subjects $(60 \%)$ did not. Also, $63 \%$ of students in the low hurry condition offered aid, $45 \%$ of students in the intermediate hurry condition offered aid, and $10 \%$ of students in the high hurry condition offered aid. Situationists argue that the results from this study by Darley and Batson (1973) offers damaging empirical evidence against the viability of the Aristotelian conception of virtuous characteristics. For example, Doris (1998) claims that this study challenges Aristotelians on the grounds that "time pressures swamped subjects' dispositions to help someone they perceived to be in need of assistance" and that the "variability of behavior with situational manipulation suggests that dispositions to moral behavior are not robust in the requisite sense" (p. 510). In agreement with Doris (1998) on this point, Harman (1999) further charges Aristotelians with committing "the fundamental attribution error of overlooking the situational factors, in this case overlooking how much of a hurry the various agents might be in" (p. 324; see also Athanassoulis, 2000, p. 215). 


\section{A. M. Croom | Integrative Psychological and Behavioral Science 48 (2014) 18-47 \\ http://dx.doi.org/10.1007/s12124-013-9249-8}

\section{Study 3: Isen and Levin (1972)}

Next, let us consider the empirical study conducted by Isen and Levin (1972). In this study an experimenter used a public payphone at the mall to set up the control and experimental conditions. Subjects in the control condition were those using the payphone that did not have a dime left in the coin return slot by the experimenter. Subjects in the experimental condition were those using the payphone that did have a dime left in the coin return slot by the experimenter. While the subjects were making their calls, a female confederate pretended to window shop while observing the subjects through a reflection in one of the store windows, so that the confederate could see when the subject was about to leave the payphone. Once the subject left the payphone the confederate started walking in the same direction as the subject, and when slightly ahead of the subject, would drop a folder full of papers in front of the subject. The experimenter set up the experimental and control payphones without informing the confederate as to condition in order to eliminate any potential bias in the confederate's performance of the paper dropping. The dependent variable in this study was whether subjects would help a stranger pick up papers that they dropped in front of them, and the independent variable was whether the subjects were in the control condition or in the experimental condition. Subjects consisted of 41 adults, 24 female and 17 male, in shopping malls located in San Francisco and Philadelphia.

The results from this study were as follows: Of the 41 total subjects, 25 subjects (16 female and 9 male) were randomly assigned to the condition without the dime and 16 subjects ( 8 female and 8 male) were randomly assigned to the experimental condition with the dime. 1 out of 25 subjects helped in the condition without the dime whereas 14 out of 16 subjects helped in the condition with the dime (see Table 2 in Isen \& Levin, 1972, p 387). A Fisher exact test on the data shows a significant relationship between receiving a dime and helping $(p<.005$ for females and $p=.025$ for males). Situationists argue that the results from this study by Isen and Levin (1972) offers damaging empirical evidence against the viability of the Aristotelian conception of virtuous characteristics. For example, Doris (1998) claims that this study challenges Aristotelians on the grounds that it "exemplifies a 70-year "situationist" experimental tradition in social and personality psychology, a tradition which has repeatedly demonstrated that the behavioral reliability expected $[\ldots]$ is not revealed in the systematic observation of behavior" (p. 504).

\section{Study 4: Milgram (1963)}

Finally, let us consider the empirical study conducted by Milgram (1963; also later discussed as Experiment 5 in Milgram, 1974). In this study an experimenter informed subjects that they would 
A. M. Croom | Integrative Psychological and Behavioral Science 48 (2014) 18-47

http://dx.doi.org/10.1007/s12124-013-9249-8

be participating in an experiment aiming to study the effects of punishment on learning. The subject served as the "teacher" while a confederate served as the "learner" in a learning scenario consisting of a word-pair association task, and the subject was instructed by the experimenter to administer electric shocks of increasing intensity to the learner for each incorrect response the learner provided during the word-pair association task. The experimenter instructed the subject to give the learner 10 seconds to respond to each question, but to treat the absence of a response from the learner as a wrong answer in which case they were to be shocked as usual. A simulated shock generator ranging from 15 to 450 volts was used to administer electric shocks as punishment to the learner for an incorrect or lack of response, with 15 volts representing the onset of "Slight Shock," 75 volts representing the onset of "Moderate Shock," 135 volts representing the onset of "Strong Shock," 195 volts representing the onset of "Very Strong Shock," 255 volts representing the onset of "Intense Shock," 315 volts representing the onset of "Extreme Intensity Shock," 375 volts representing the onset of "Danger: Severe Shock," and finally, 435 and 450 volts representing the most extreme level of shock labeled "XXX." Although the learner gives no sign of protest before 300 volts is administered, the learner starts pounding on the wall in protest once the 300 -volt threshold is crossed. Once the 315 -volt threshold is crossed, the learner becomes silent and no longer continues responding to the word-pair association task. If at any time during the experiment the subject expressed an unwillingness to continue administering shocks to the learner, the experimenter would respond to the learner with a series of 4 prods of increasing force: (1) "Please continue, or Please go on," (2) "The experiment requires that you continue," (3) "It is absolutely essential that you continue," and (4) You have no other choice, you must go on" (see Milgram, 1963, p. 374). In this study the dependent variable was the maximum shock the subject was willing to administer to the learner under the direction of the experimenter before refusing to continue with the study any further. The experimenter was a 31 year-old adult male biology teacher, the learner was a 47 year-old adult male, and subjects consisted of 40 adult males between 20 and 50 years of age. The experiment was conducted in an elegant laboratory at Yale University.

The results from this study were as follows: All 40 subjects administered electric shocks at least up to the 300-volt level, at which point the learner starts pounding on the wall in protest. Yet 14 of the 40 subjects did defy the experimenter at some point during the experiment by refusing to administer any further electric shocks to the learner. Of these 14 subjects that defied the experimenter, 5 of them refused to administer shocks past the 300-volt level, 4 refused to administer shocks past the 315-volt level, 2 refused to administer shocks past the 330-volt level, 1 refused to administer shocks past the 345-volt level, 1 refused to administer shocks past the 360-volt level, and 1 refused to administer shocks past the 375-volt level. The remaining 26 of the 40 subjects fully obeyed the experimenter through the end by administering electric shocks up to the maximum 450- 
A. M. Croom | Integrative Psychological and Behavioral Science 48 (2014) 18-47

http://dx.doi.org/10.1007/s12124-013-9249-8

volt level (see Table 2 in Milgram, 1963, p. 376). Situationists argue that the results from this study by Milgram (1963) offers damaging empirical evidence against the viability of the Aristotelian conception of virtuous characteristics. For example, Harman (1999) claims that this study challenges Aristotelians on the grounds that "all subjects were willing to go at least to the 300 volt level" (p. 322) while Doris (1998) further maintains that "subjects who reluctantly consented to torture the recalcitrant "victim" [...] were overridden by misguided feelings of obligation, or perhaps intimidation, generated by the experimenter's insistence on their continued participation in the "learning experiment" (p. 510).

We have now discussed the details and results of the studies conducted by Hartshorne and May (1928), Darley and Batson (1973), Isen and Levin (1972), and Milgram (1963), as well as how situationists have used the results from these studies to challenge the Aristotelian conception of virtuous characteristics. The viability of an Aristotelian moral psychology, and the notion of characteristics that it invokes, would require "cross-situational consistency" in behavior, that is to say, "behavioral reliability" across a range of "relevant eliciting situations" (see Doris, 1998, p. 506-507). “To have different character traits," Harman (1999) argues, subjects "must be disposed to act differently in the same circumstances" (p. 317). Yet the empirical evidence from these four studies has shown, so situationists have argued, that human beings fail to demonstrate this requisite crosssituational consistency and behavioral reliability. Harman (1999) sums up the situationist lesson for Aristotelians quite succinctly: "Empirical studies designed to test whether people behave differently in ways that might reflect their having different character traits have failed to find relevant differences [...] we must conclude that there is no empirical basis for the existence of character traits" (p. 316).

However, the aim of the next 4 sections, $7-10$, is to show that a more careful analysis of the details and results of the studies conducted by Hartshorne and May (1928), Darley and Batson (1973), Isen and Levin (1972), and Milgram (1963), respectively, do not in fact support the situationist challenge against Aristotelian moral psychology, as situationists often suppose.

\section{Reconsidering Study 1: Hartshorne and May (1928)}

Recall study 1, the Hartshorne and May (1928) study. Situationists argued that the results from this study provide empirical evidence demonstrating that subjects behave differently across situations in which they ought to behave similarly if they in fact possessed the relevant characteristics. Since situationists interpreted the result that the experimenters found relatively low inter-correlations with an average of approximately +0.20 between any two measures for altruism, honesty, and selfcontrol (e.g., +0.23 for altruism) as showing that behavioral variation is due to different situations rather than different characteristics, they argued that the results from this study undermine the 
A. M. Croom | Integrative Psychological and Behavioral Science 48 (2014) 18-47

http://dx.doi.org/10.1007/s12124-013-9249-8

Aristotelian thesis (A1) and instead support the situationist thesis (S1). Since situationists also interpreted the results from this study as showing that the possession of virtuous characteristics (such as honesty) are not highly correlated with the possession of other virtuous characteristics (such as self-control), they argued that the results from this study undermine the Aristotelian thesis (A3) and instead support the situationist thesis (S3).

The first problem with this situationist use of study 1 concerns the fact that it neglects the amount of behavioral consistency that this study does in fact find. Study 1 did find, after all, some significant correlation between any two measures for altruism, honesty, and self-control. The fact that there was an average of approximately +0.20 correlation between any two measures for altruism, honesty, and self-control is a replicable finding suggestive of at least some consistency in behavior (see also Rushton, Chrisjohn, \& Fekken, 1981). This fact cannot simply be ignored, so while not denying the situationist point that situational contexts are important to consider in understanding human behavior, they have gone too far in interpreting this as evidence that behavioral consistency does not exist at all (cf. Harman, 1999, p. 316). Moreover, it was found that within these different situations some of the children were more honest, more likely to resist temptation, and more helpful than others (Sigelman \& Rider, 2009, p. 390), which cannot be explained by situational factors alone since these behavioral differences were found within the same situations.

The second problem with this situationist use of study 1 concerns the fact that it focuses primarily on discussing correlations between single measures instead of combinations of exemplars, and in so doing has neglected to discuss correcting for error variance. It has previously been discussed in the psychological literature that sampling a number of exemplars is often more reliable than using single measures since a fair amount of randomness will usually be present in any single measure (see also Spearman, 1910; Eysenck, 1939; Rushton, Chrisjohn, \& Fekken, 1981). It has been suggested in the literature that combining and summing over a number of exemplars facilitates the averaging out of randomness (i.e., error variance), providing for better predictability of behavior (Rushton, Chrisjohn, \& Fekken, 1981). In the Hartshorne and May (1928) study in particular, although relatively low correlations of approximately +0.20 were found between single measures of altruism, honesty, and self-control (e.g., +0.23 for altruism), much higher correlations of approximately +0.50 to +0.60 were found when the five measures were combined into batteries (e.g., +0.61 for altruism). As Hartshorne, May, and Maller (1929) mentioned in the second volume of Studies in the nature of character, "The correlation between the total service score and the total reputation score is $0.61[\ldots]$ Although this seems low, it should be borne in mind that the correlations between test scores and ratings for intelligence seldom run higher than 0.50 " (p. 107). Perceptions of subjects by both teachers and peers were also found to highly agree (e.g., $r=0.81$ for altruism; see Hartshorne, May, \& Maller, 1929, p. 91), which is suggestive of significant behavioral consistency 
A. M. Croom | Integrative Psychological and Behavioral Science 48 (2014) 18-47

http://dx.doi.org/10.1007/s12124-013-9249-8

from the subjects. Indeed, more recent analyses of the data along with further studies have suggested that children behave more consistently than Hartshorne and May (1928) originally concluded (see Burton, 1963; Hoffman, 2000; Kochanska \& Aksan, 2006).

The third problem with this situationist use of study 1 concerns the fact that it misleadingly over-generalizes the results from a study whose population group consisted of children to enforce subsequent conclusions concerning all human beings. Clearly children constitute only a subset of all human beings, and it is not plausible that a group consisting only of children is what we (or Aristotle) would suspect as being the most relevantly consistent or stable in behavior anyways; it is not when we are children, but when we grow older that we get "set in our ways" (Westerhoff, 2008, p. 44). Recent empirical studies have shown, for instance, that behavior is not as closely interrelated in childhood as it is in adolescence or adulthood (Blasi, 1980; Sigelman \& Rider, 2009, p. 390), and Aristotle would not have found this result surprising. For he was quite insistent in Nicomachean Etbics that children especially were in need of proper rearing, since "longing for pleasure is present in them especially [...] and bombards from all sides someone who lacks sense" (NE 1119b5-15; see also NE 1142a10-15). It is partly because children are especially suceptible to being bombarded with varying pleasures "from all sides" that they especially must be habituated and educated correctly (NE 1104b5-10). As Aristotle writes, "It makes no small difference, then, whether one is habituated in this or that way straight from childhood but a very great difference - or rather the whole difference" (NE 1103b20-25). So it is clear from this that Aristotle did not support claims to the effect that children come preprogrammed with the virtues already (NE 1103a15-20), so he would not readily concede that results from studies on the characteristics of children can carry over straightforwardly to subsequent conclusions about the characteristics of adults or all human beings. Given that recent empirical studies have shown that childrearing practices influence the prosocial initiations of children towards victims of distress (Zahn-Waxler, Radke-Yarrow, \& King, 1979; Zahn-Waxler \& RadkeYarrow, 1990), the results from the Hartshorne and May (1928) study could just as easily be viewed as supporting the Aristotelian point that children especially are in need of rearing and that characteristics require continual cultivation from childhood throughout adulthood (NE 1179b301180a5). So niether Aristotle, nor ourselves, would expect results from studies on children to be straighforwardly carried over to conclusions concerning all human beings, which is precisely what situationists have done.

Given our considerations on these three problems with the situationist use of study 1, we can conclude that the situationist is not warranted in claiming that the results from the study by Hartshorne and May (1928) undermine the Aristotelian theses (A1) and (A3) and instead support the situationist theses (S1) and (S3). 
A. M. Croom | Integrative Psychological and Behavioral Science 48 (2014) 18-47

http://dx.doi.org/10.1007/s12124-013-9249-8

\section{Reconsidering Study 2: Darley and Batson (1973)}

Next recall study 2, the Darley and Batson (1973) study. Situationists argued that the results from this study provide empirical evidence demonstrating that subjects behave differently in situations of pressure than they ought to behave if they in fact possessed the relevant characteristics. Since situationists interpreted the result that $63 \%$ of students in the low hurry condition offered aid, $45 \%$ of students in the intermediate hurry condition offered aid, and $10 \%$ of students in the high hurry condition offered aid as showing that characteristics are not resistant to contrary situational (temporal) pressures, they argued that the results from this study undermine the Aristotelian thesis (A2) and instead support the situationist thesis (S2). Since situationists also interpreted the results from this study as showing that behavioral variation is due to different situations (such as whether subjects were in a low hurry, intermediate hurry, or high hurry condition) rather than different characteristics, they also argued that the results from this study undermine the Aristotelian thesis (A1) and instead support the situationist thesis (S1).

The first problem with this situationist use of study 2 concerns the fact that it neglects the amount of behavioral robustness that this study does in fact find. Study 2 did find, after all, some significant resistance to situational (temporal) pressures, which may be taken to represent at least some robustness in behavior. More specifically, it was found that 16 of the 40 subjects (40\%) offered some form of direct or indirect aid to the victim. In the low hurry condition $63 \%$ of students still offered aid when $37 \%$ of them did not, in the intermediate hurry condition $45 \%$ of students still offered aid when $55 \%$ of them did not, and in the high hurry condition $10 \%$ of students still offered aid when $90 \%$ of them did not. It is a fact that cannot simply be ignored that within each situation we find differences in behavior, which means that situational considerations alone are insufficient for explaining behavior. "To have different character traits," Harman (1999) argues, subjects "must be disposed to act differently in the same circumstances" (p. 317), and it is clear from this study that for each condition we do in fact find behavioral differences within the same situations. So in holding that "we are safest predicting, for a particular situation, that a person will behave pretty much as most others would" (Doris, 1998, p. 507), the situationist fails to provide an account nuanced enough to explain behavioral differences within the same situations, which is what we in fact find.

The second problem with this situationist use of study 2 concerns the fact that it misleadingly over-generalizes the results from a study whose population group consisted of students to enforce subsequent conclusions concerning all human beings. Clearly students constitute only a subset of all human beings, and it is not plausible that a student group is what one would suspect to be the most relevantly consistent or stable in behavior anyways; instead, one would suspect the most relevantly consistent and stable behavior from instructors or leaders. Those that are students are 
A. M. Croom | Integrative Psychological and Behavioral Science 48 (2014) 18-47

http://dx.doi.org/10.1007/s12124-013-9249-8

typically in the process of encountering novel situations in which they are not already expert so that they can learn and grow, and they should be granted some forgiveness for their lack of grace and the mistakes they will invariably make. ${ }^{6}$ It may be that this kind of situation was a novel one for the students and that, only after going through it and being able to reflect over it afterwards, could the students subsequently acquire a more seasoned eye and readiness to act appropriately. In fact, in their study published in Journal of Cognitive Neuroscience, Wills, Lavric, Croft, and Hodgson (2007) found that subjects learned more rapidly about cues for which they initially made incorrect predictions than about cues for which they initially made correct predictions, and that this is partly due to the fact that error-related events attract more attention from subjects (for further details regarding these results see Wills, Lavric, Croft, \& Hodgson, 2007, especially p. 847-849, 851-852). So it is possible that making and learning from errors in difficult situations like these may be just what is needed to build experienced seminarians, and may be what makes some seminary instructors as good as they are $(\mathrm{NE}$ 1143b10). It is the older people with a more experienced eye, such as instructors or leaders, that are expected to have already learned and earned their stripes, and thus best able to see the most correct course of action in situations like these. That is why the teachers are put in the position of teaching, and the students are there to learn. A similar experimental study investigating the behavior of Princeton Theological Seminary instructors instead of students may prove more forceful and interesting, but was not conducted.

The third problem with this situationist use of study 2 concerns the fact that it misleadingly over-generalizes the results from a study whose population group consisted of seminarians to enforce subsequent conclusions concerning all human beings. Clearly seminarians constitute only a subset of all human beings, but what is not clear is that seminarians constitute a population group that is most relevantly trained to pick up on and aptly deal with the situation of encountering complete strangers in alleyways, at least some of which are likely to be dangerous or sick. What is not being questioned here is whether seminarians are well intentioned and well trained to provide the services that are actually within the purview of their specialization and relevant experience - such as preaching, giving lectures, and performing various religious rites and ceremonies - but whether they have received the kind of training relevant to aptly deal with the kind of situation in which they have been tested. Seminarians are not, after all, trained or behaviorally conditioned to engage with potentially dangerous individuals, or to act as first responders in medical cases. Seminarians are not paramedics, although both provide services that are beneficial to the public in their own ways. Aristotle makes a relevant point in Nicomachean Ethics when he claims that certain characteristics only come about by

${ }^{6}$ When we see that one's actions result from "ignorance pertaining to the various particulars, both the circumstances of the action and what it concerns," Aristotle suggests, then "there is both pity and forgiveness" (NE 1111a). 
A. M. Croom | Integrative Psychological and Behavioral Science 48 (2014) 18-47

http://dx.doi.org/10.1007/s12124-013-9249-8

continuously engaging in certain corresponding forms of action: "the activities that pertain in each case produce people of a corresponding sort. This is clear from those who take the appropriate care with a view to any contest or action whatever, for they are continually engaged in the relevant activity $[\ldots]$ the corresponding characteristics come from engaging in a given activity" (NE 1114a5-10, my emphasis; see also NE 1141b-20). Another passage from Nicomachean Ethics is particularly noteworthy here, in light of this point regarding relevant experience:

experience of particular things seems to be courage as well $[\ldots]$ Yet different people are experienced in different things, and in matters of war, it is the professional soldiers who are such. For there seem to be many false alarms in war, which professional soldiers especially see through. Hence they appear courageous, because the others do not know what these false alarms are. Then too, professional soldiers are especially able to make an attack and not suffer one, as a result of their experience, since they are able to use their weapons and possess the sorts of things that are most excellent for both making an attack and not suffering one oneself. They, then, are like armed men fighting unarmed ones or trained athletes contesting with private amateurs. (NE 1116b5-10)

In this case of helping complete strangers in alleyways, it may be that paramedics are like "trained athletes" and seminarians are like "private amateurs," considering the kinds of experience that are actually possessed by each. For paramedics or pararescuemen, who have paid the price for their kind of excellence through rigorous practice and accumulated experience, responding to people in physical need and in dangerous situations has become part of their second nature (see Giunta, 2012). For instance, recall how on 2 January 2011 Wesley Autrey saw a stranger suffer from a seizure and fall onto the train tracks of a New York City subway. Autrey immediately leapt out in front of the oncoming train and covered the man's body with his own as the train passed over them, enabling both to survive the situation unharmed (see Trump, 2007; Lerner, 2011). Recall that situationists suggest that "we are safest predicting, for a particular situation, that a person will behave pretty much as most others would" (Doris, 1998, p. 507), but it seems unreasonable to suppose that most others would act as Autrey did on that day. In fact, many others that were also there to witness the event in the New York City subway did not help as Autrey did. So how are we to understand the fact that Autrey, but not others, helped the unfortunate man that was almost killed on the tracks of a New York City subway? Learner (2011), in his chapter published in Happiness and virtue beyond east and west, makes the following reasonable suggestion: 
A. M. Croom | Integrative Psychological and Behavioral Science 48 (2014) 18-47

http://dx.doi.org/10.1007/s12124-013-9249-8

spontaneous and noble action on behalf of a stranger is within the realm of human possibility. Thoughtful readings of the incident indicate just why, however, even the most altruistic among us might not act as Autrey did. A navy veteran, he had been trained to move quickly in stressful situations. Not only was Autrey able to immediately empathize with the man he beheld, but he also could draw on his military past, a way of responding that had long become for him automatic, his way of being in the world. (p. 101)

In light of such considerations, it is not clear that seminarians should be expected to act with the kind of excellence as a first responder, or in a way that was most relevant to the situation they had encountered. A case could be made that, although seminarians are expected to act as exemplars under the light of some kinds of actions, they need not be expected to act as exemplars under the light of all kinds of actions. Expectations ought to take relevance into consideration. Perhaps testing the inexperienced on tasks outside the purview of their specialization and relevant experience is not the most effective way of testing for the characteristics that they have actually developed and are most relevant to them. A similar experimental study investigating the behavior of paramedics instead of seminarians, for example, may prove more forceful and interesting, but was not conducted.

The fourth problem with this situationist use of study 2 concerns the fact that it simply assumes without argument how the subjects ought to have acted in these situations without taking into consideration their reasons for acting. Specifically, situationists simply assume that stopping to help a stranger in an alleyway is what one ought to have done in this case irrespective of the reason one was in a hurry. Up to now, through the first three problems we discussed regarding the situationist use of study 2 , we have simply conceded this point to the situationist for the sake of argument, but what is being focused on here is whether this concession is as legitimate as often supposed. For example, in discussing study 2 Prinz (2009) expresses the view that:

the desire to be on time may be admirable in other contexts, but here the salient distress of another human being should trump. Sreenivasan [2002] implies that there is reason to abandon virtue in these cases, but I think he mistakes rationalization for reason. Is it really reasonable to leave a moaning stranger slouched in [a] doorway simply because you are in a hurry? What appointment could be so important? (p. 123)

But here Prinz (2009) neither provides an argument for why helping a stranger should trump being on time to a promised appointment, nor highlights the fact that here the subject is placed in a no-win situation: if the subject keeps his promise by making it to the appointment on time he will be persecuted for failing to help the stranger, and if the subject helps the stranger he will be persecuted 
A. M. Croom | Integrative Psychological and Behavioral Science 48 (2014) 18-47

http://dx.doi.org/10.1007/s12124-013-9249-8

for failing to keep his promise by making it to the appointment on time. By placing the subject in this kind of no-win situation, the subject can be condemned for whichever action he chooses, and the situationist is handed a rather cheap victory. But choices for action are not made in a vacuum, but rather involve tradeoffs. The question of whether to use your time to help a stranger may seem obvious, but the question of whether to use your time to help a stranger instead of making it to your brother's baptism or catching a flight out of town to visit your dying mother is more complicated and realistic. Of course one should help others when costs and alternative courses of action need not be taken into consideration, but it is not clear that one should help other strangers irrespective of the reasons there may be to not help. For a young seminary student, keeping one's promise to a seminary leader or other seminary students may reasonably trump many other decisions, as one has made a direct commitment to their seminary obligations whereas one has made only an indirect commitment (if any at all) to helping others when one practically can. The seminary student may think that they are directly responsible for arriving on time to give the lecture they promised at Princeton Theological Seminary but only indirectly responsible for helping as many others as they practically can. Given the fact that we must work to survive and so cannot spend every bit of our energy, money, and time in charity, there are inevitably times in which one must forgo charity for the sake of living, and for the sake of saving so that one may live tomorrow. The point is well put by Aristotle in his discussion of liberality in Nicomachean Ethics, when he says that the liberal person "is not careless with his own possessions [such as money and time], since he wishes, at least, to aid some people through these very possessions. And he will not give to just anyone, so that he may be able to give to whom he ought and when and where it is noble to do so" (NE 1120a25-1120b). Although it may be praiseworthy to help a stranger, if one must choose between the mutually exclusive options of helping a stranger or helping several respected colleagues instead, it may be more praiseworthy to help the latter, given that you cannot help them both. This point is fleshed out in another of Aristotle's remarks:

He will associate differently among people of worth than among people at random, just as he will associate differently also with those who are more or less known to him, and similarly in the case of other relevant differences, assigning to each what is fitting. And while he chooses to contribute to the pleasure of others for its own sake and is cautious about causing others pain, he is guided by the consequences at stake [...] And for the sake of a great pleasure in the future, he will cause a little pain now. Such, then, is the person marked by the middle characteristic. (NE 1127a; see also NE 1126b25) 
A. M. Croom | Integrative Psychological and Behavioral Science 48 (2014) 18-47

http://dx.doi.org/10.1007/s12124-013-9249-8

So if the seminary student has reason to believe that his seminary leader as well as other students are depending on him to make his appointment on time, and he must make a less than ideal choice between helping a stranger in an alleyway or instead helping many of his religious peers, it cannot be assumed without argument that helping the stranger is the best, most virtuous, choice given this nowin situation. Furthermore, the seminary student may think that if they fail to help the stranger now there will always be plenty of other opportunities to help strangers later, since there are over 643,000 people that are homeless in the US on any given night (Eng, 2012; see also Witte, 2012). But if the seminary student fails to keep their promised appointment, then their very career as a future seminarian may be put on the line, and if one fails to become a seminarian then one might resultantly fail to help many others later in the ways that seminarians are excellent at helping. Prinz (2009) charges Sreenivasan (2002) with mistaking rationalization for reason, but I believe that this charge is misguided in that the question Sreenivasan (2002) has raised is not whether one should act virtuously in these cases but rather whether helping in these cases is what counts as the most virtuous course of action given the reasons one must consider (see Sreenivasan, 2002, p. 60-61). So the assumption that helping strangers is always best, irrespective of one's reasons and alternative choices, is not as straightforwardly correct as situationists often assume, since one can be persecuted here either way. Even Darley and Batson (1973) concluded with this point in the final analysis of their study:

Why were the seminarians hurrying? Because the experimenter, whom the subject was helping, was depending on him to get to a particular place quickly. In other words, he was in conflict between stopping to help the victim and continuing on his way to help the experimenter. And this is often true of people in a hurry; they hurry because someone depends on their being somewhere. Conflict, rather than callousness, can explain their failure to stop. (p. 108, original emphasis)

Given our considerations on these four problems with the situationist use of study 2, we can conclude that the situationist is not warranted in claiming that the results from the study by Darley and Batson (1973) undermine the Aristotelian theses (A1) and (A2) and instead support the situationist theses (S1) and (S2).

\section{Reconsidering Study 3: Isen and Levin (1972)}

Next recall study 3, the Isen and Levin (1972) study. Situationists argued that the results from this study provide empirical evidence demonstrating that subjects behave differently in situations of positive affect than they ought to behave if they in fact possessed the relevant 
A. M. Croom | Integrative Psychological and Behavioral Science 48 (2014) 18-47

http://dx.doi.org/10.1007/s12124-013-9249-8

characteristics. Since situationists interpreted the result that 1 out of 25 subjects helped in the condition without the dime whereas 14 out of 16 subjects helped in the condition with the dime as showing that characteristics are not resistant to contrary situational (affective) pressures, they argued that the results from this study undermine the Aristotelian thesis (A2) and instead support the situationist thesis (S2). Since situationists also interpreted the results from this study as showing that behavioral variation is due to different situations (such as whether subjects were in a condition of neutral or positive affect) rather than different characteristics, they argued that the results from this study also undermine the Aristotelian thesis (A1) and instead support the situationist thesis (S1).

The major problem with this situationist use of study 3 concerns the fact that this was not a replicable finding. For instance, in a subsequent study conducted by Blevins and Murphy (1974) that used a similar experimental scenario, the experimenters found that in the condition without the dime 15 of the 35 total subjects helped when 20 out of 35 of them did not, and that in the condition with the dime 6 of the 15 total subjects helped when 9 out of 15 of them did not. In contrast to the findings of Isen and Levin (1972), Fisher exact tests from this study by Blevins and Murphy (1974) indicated that there was no relationship between finding a dime and helping for either males or females (see Blevins \& Murphy, 1974, p. 326). Further, in another subsequent study conducted by Weyant and Clark (1976), they found that subjects that found a dime did not mail an apparently lost letter more often than those that did not find a dime. The experimenters found that in the condition without the dime 15 of the 52 total subjects helped when 37 out of 52 of them did not, and that in the condition with the dime 12 of the 54 total subjects helped when 42 out of 54 of them did not. Once again, in contrast to the results from Isen and Levin (1972), Fisher exact tests from this study by Weyant and Clark (1976) indicated that there was no relationship between finding a dime and helping for either males or females (see Table 2 in Weyant \& Clark, 1976, p. 109). Thus, in at least two subsequent studies that attempted to replicate the effect of feeling good on helping that was reported by Isen and Levin (1972), no such effect had been found.

Given our considerations on this major problem with the situationist use of study 3 , we can conclude that the situationist is not warranted in claiming that the results from the study by Isen and Levin (1972) undermine the Aristotelian theses (A1) and (A2) and instead support the situationist theses (S1) and (S2).

\section{Reconsidering Study 4: Milgram (1963)}

Finally, recall study 4, the Milgram (1963) study. Situationists argued that the results from this study provide empirical evidence demonstrating that subjects behave differently in situations under authority than they ought to behave if they in fact possessed the relevant characteristics. Since 
A. M. Croom | Integrative Psychological and Behavioral Science 48 (2014) 18-47

http://dx.doi.org/10.1007/s12124-013-9249-8

situationists interpreted the result that all 40 subjects administered electric shocks at least up to the 300-volt level as showing that characteristics are not resistant to contrary situational (authoritative) pressures, they argued that the results from this study undermine the Aristotelian thesis (A2) and instead support the situationist thesis (S2).

The first problem with this situationist use of study 4 concerns the fact that it neglects the amount of behavioral robustness that this study does in fact find. Study 3 did find, after all, some significant resistance to situational (authoritative) pressures, which may be taken to represent at least some robustness in behavior. More specifically, in this study it was found that 14 of the 40 subjects did in fact disobey the experimenter at some point by refusing to continue administering shocks even though 26 of the 40 subjects fully obeyed the experimenter to the maximum 450 -volt level. Granted, all 40 subjects administered shocks at least up to the 300-volt level, but also recall that before this point the learner that was being shocked was not even protesting to the shocks. It was only once the 300 -volt level had been reached that the learner would begin to start pounding on the wall in protest, and at this point subjects did start disobeying the experimenter. Of the 14 subjects that defied the experimenter at some point during the experiment by refusing to administer any further shocks to the learner, 5 of them refused to administer shocks past the 300-volt level, 4 refused to administer shocks past the 315-volt level, 2 refused to administer shocks past the 330-volt level, 1 refused to administer shocks past the 345-volt level, 1 refused to administer shocks past the 360-volt level, and 1 refused to administer shocks past the 375-volt level. This disobedience cannot simply be ignored, and it is not insignificant to consider that this disobedience also persisted through four increasingly forceful prods by the experimenter to continue. "To have different character traits," Harman (1999) argues, subjects "must be disposed to act differently in the same circumstances" (p. 317), and it is clear from this study that we do in fact find behavioral differences within the same situation. So in holding that "we are safest predicting, for a particular situation, that a person will behave pretty much as most others would" (Doris, 1998, p. 507), the situationist fails to provide an account nuanced enough to explain the behavioral differences within this same situation (see also Athanassoulis, 2000, p. 217).

The second problem with this situationist use of study 4 concerns the fact that it simply assumes without argument that it was obvious for the subject to have reasonably disobeyed the experimenter before the point at which the learner starts protesting (i.e., at the 300-volt level) irrespective of the subject's reasons for continuing. The focus of this point is to question whether this assumption is legitimate. There were, after all, strong prima facie reasons to believe in the trustworthiness of the experimenter and situation. Recall that the experimenter was a biology teacher dressed in a gray technician's coat, and that the situation where this experiment took place was "on the grounds of Yale University in the elegant interaction laboratory," which Milgram (1963) 
A. M. Croom | Integrative Psychological and Behavioral Science 48 (2014) 18-47

http://dx.doi.org/10.1007/s12124-013-9249-8

acknowledges, "is relevant to the perceived legitimacy of the experiment" (p. 72). One might reasonably think that if you can trust anyone to run a psychology experiment, it is probably someone that teaches biology and run an elegant lab in Yale's department of psychology, so subjects had prima facie reason not to suspect any foul play, especially when no reason had yet been given to think otherwise. In fact, the experimenter explicitly informed subjects at the outset that, "Although the shocks can be extremely painful, they cause no permanent tissue damage" (Milgram, 1963, p. 373). Is a bit of pain to someone that willingly volunteered for it the price that must be paid for the progress of science and humanity as a whole? We all pay our dues toward the greater good once in a while, don't we? So maybe one who is not expert in cases like these should, for at least the time being, defer to the expert until provided with strong reasons to think otherwise. And no strong reasons were provided prior to the 300-volt level, where the learner would start protesting. Further, in Experiment 13 conducted by Milgram (1974), he found that when "an ordinary man" instead of an experimenter with presumed authority directed the subject to administer shocks to the learner, significantly more subjects disobeyed the experimenter: 16 of the 20 subjects disobeyed by refused to continue administering shocks when only 4 of the 20 subjects continued to fully obey by administering the maximum 450-volts. Similarly, in a related study involving soldiers at Fort Knox, Shalala (1974) found that subjects were significantly less obedient to the orders of the experimenter when the experimenter was a private instead of a lieutenant colonel. Presumably this is because the commands of everyday people do not carry the same force and legitimacy as do the commands of Yale experimenters, and the commands of privates do not carry the same force and legitimacy as do the commands of lieutenant colonels, who are both higher in status as well as more knowledgeable in their relevant respects. When the location of the experiment was changed in Experiment 10 from the elegant Yale laboratory to an office building in Bridgeport, the percentage of subjects that fully obeyed also dropped, with 19 of the 40 subjects (47.5\%) fully obeying in the office building in Bridgeport and 26 of the 40 subjects (65\%) fully obeying in the laboratory at Yale. Thus, with weaker prima facie reasons to believe in the trustworthiness of the experimenter and situation, we do find less obedient behavior, and in all cases a significant proportion of people do in fact stop administering shocks once the person being shocked starts protesting.

It is also relevant to our discussion that further empirical research has suggested that several personality variables can have an influence on obedience (see Blass, 1991). For instance, personality variables that have been suggested in the psychological literature as having an influence on obedience include (a) authoritarianism, with subjects that are more authoritarian exhibiting more obedience (see Elms \& Milgram, 1966; Elms, 1972), (b) interpersonal trust, with subjects that are more trusting exhibiting more obedience (see Miller, 1975), (c) level of moral judgment, with subjects with lower levels of moral judgment exhibiting more obedience (see Milgram, 1974; Blass, 1991), (d) level of 
A. M. Croom | Integrative Psychological and Behavioral Science 48 (2014) 18-47

http://dx.doi.org/10.1007/s12124-013-9249-8

social intelligence, with subjects with lower levels of social intelligence exhibiting more obedience (see Burley \& McGuinness, 1977), (e) hostility, with subjects that are more hostile exhibiting more obedience (see Haas, 1966), and (f) locus of control (Rotter, 1990), with subjects that are more external than internal exhibiting more obedience (see Holland, 1967; Miller, 1975). Although it has often been complained in the literature that personality traits are not often predictive of behavior, Fleeson and Gallagher (2009) recently performed a meta-analysis of 15 experience-sampling studies conducted over the course of 8 years (ranging over 20,000 reports of trait manifestation in behavior) and found that traits were actually strongly predictive of individual differences in the manifestation of traits in behavior, predicting average levels with correlations between +0.42 and +0.56 (approaching +0.60 for stringently restricted studies; see Table 3 in Fleeson \& Gallagher, 2009, p. 1104).

Given our considerations on these two problems with the situationist use of study 4, we can conclude that the situationist is not warranted in claiming that the results from the study by Milgram (1963) undermine the Aristotelian thesis (A2) and instead support the situationist thesis (S2).

\section{Reconsidering Aristotelian moral psychology}

In the previous sections 7-10, we went over 10 points of concern with the situationist use of studies 1-4 and found that the situationist did not have a strong case in attempting to use the results from these studies to argue against the viability of Aristotelian moral psychology. In fact, in sections 7-10 we also found that some of the claims Aristotle makes may actually provide insight into the situationist misinterpretation and misuse of these empirical results. For instance, we saw how Aristotle pointed out that the behavior of children may be less interrelated than the behavior of adults (see for instance NE 1119b5-15, 1142a10-15, 1143b10; see also 1103b20-25, 1104b5-10) and that considerations of human behavior must take into account both one's reasons for acting (see for instance NE 1105a30, 1107a-5, 1115b10) as well as the relevance of one's characteristics with respect to a given situation (see for instance NE 1114a5-10, 1116b5-10, 1141b-20). But the situationist challenge fails for more than the fact that it advances exaggerated claims that are not supported by the empirical evidence. The second reason that the situationist challenge fails is because it does not provide an accurate account of Aristotelian moral psychology that is grounded in original Aristotelian text. A solid attack against Aristotelian moral psychology requires getting the empirical facts as well as Aristotle's own account right. Although this final section cannot provide a fully detailed and comprehensive account of Aristotle's moral psychology, it will take up the more modest aim of considering several points that suggest that the situationist has not presented a sufficiently adequate account of the Aristotelian view. 
A. M. Croom | Integrative Psychological and Behavioral Science 48 (2014) 18-47

http://dx.doi.org/10.1007/s12124-013-9249-8

First, let us reconsider how situationists have presented the Aristotelian view of characteristics, and how their conception of Aristotelian characteristics motivates their ascription of theses (A1) and (A2) to Aristotelians. Recall that Harman (1999) explained the Aristotelian view of characteristics as consisting in broad-based dispositions rather than narrow-based dispositions (p. 318). In order to explicate this distinction between broad-based and narrow-based dispositions, Prinz (2009) provides the example that "being talkative is broad-based, while being talkative in the cafeteria at lunch is not" (p. 119). On this situationist characterization, a broad-based disposition such as "being talkative" consists in a disposition that is unqualified and context-insensitive; the disposition of "being talkative" as such is not qualified to certain situations and sensitive to certain contexts. On the other hand, according to the situationist, a narrow-based disposition such as "being talkative in the cafeteria at lunch" consists in a disposition that is qualified and context-sensitive; the disposition of "being talkative in the cafeteria at lunch" is qualified to certain situations and sensitive to certain contexts, namely, those pertaining to the cafeteria and lunch. The situationist claims that Aristotelians view characteristics as broad rather than narrow. Further, because the situationist views Aristotelian characteristics as broad-based dispositions that are unqualified and context-insensitive, they assume that Aristotelian characteristics must also be invariant across all situations, as expressed in (A1), and rigidly robust in all situations, as expressed in (A2). The reasoning here is that if broad-based dispositions such as "being talkative" are unqualified then they should be invariant across situations (for if not, then they would be qualified by these varying situations), and if broad-based dispositions such as "being talkative" are context-insensitive then they should resist contrary situational pressures (for if not, then they would be sensitive to these situational pressures).

Yet it is questionable whether the Aristotelian is really committed to the view that characteristics are broad-based in the way that the situationist has accounted, or that their account is supported by firm textual evidence, for Aristotle makes several explicit claims in Nicomachean Ethics as well as Politics suggesting that the situationist account is problematic. For example, at 1148b5-10, Aristotle explicitly discusses the point about characteristics in the qualified rather than unqualified sense:

people say "lack of self-restraint" while specifying something additional about each case, as people say, for example, "bad doctor" or "bad actor" about someone they would not say is bad simply $[\ldots]$ one would not in these cases speak of their being bad simply $[. .$.$] Hence we$ assert that someone is lacking self-restraint, adding also "when it comes to spiritedness," just as in the cases of honor and gain as well. (NE 1148b5-10) 
A. M. Croom | Integrative Psychological and Behavioral Science 48 (2014) 18-47

http://dx.doi.org/10.1007/s12124-013-9249-8

Although situationists often assume that Aristotelians conceive of individuals in such broad terms as "a person of good character" or "bad character" (Harman, 1999, p. 318-319), 7 i.e., as having character that is unqualifiedly good or unqualifiedly bad, we can see that this is certainly not the view Aristotle is presenting at 1148b5-10 of Nicomachean Ethics. In this passage, Aristotle is not suggesting that the person lacking self-restraint is "bad" simply (lacking all virtues in all respects), nor is Aristotle even suggesting the weaker claim that the person is lacking in "self-restraint" simply (lacking the particular virtue of self-restraint (temperance) in all respects), but is merely suggesting that the person lacks self-restraint "when it comes to spiritedness" (lacking the particular virtue of self-restraint (temperance) with respect to spiritedness). Earlier at 1096b25 of Nicomachean Ethics, we also find Aristotle explicitly claiming that "the definitions of honor, prudence, and pleasure are distinct and differ in the very respect in which they are goods. It is not the case, therefore, that the good is something common in reference to a single idea" (NE 1096b25; see also 1096a15-30). Here Aristotle is explaining that there are goods with respect to honor, goods with respect to prudence, and goods with respect to pleasure, but not that these are all instances of some common unqualified good. Aristotle repeatedly warns against speaking in such generalities, and at 1260a20-25 of Politics, Aristotle makes himself especially clear on this point by advising that "people who talk in generalities, saying that virtue is a good condition of the soul, or correct action, or something of that sort, are deceiving themselves. It is far better to enumerate the virtues, as Gorgias does, than to define them in this general way" (Pol. 1260a20-25; see also NE 1127a15). Thus, it is clear that the situationist claim that Aristotelians view characteristics as broadly unqualified dispositions is not only unsupported by the text, but also does not cohere with many points we actually find Aristotle making in both Nicomachean Ethics and Politics.

Next, the situationist assumption that Aristotelians view characteristics as broadly contextinsensitive dispositions also appears unsupported by the text, for Aristotle makes several explicit claims in Nicomachean Ethics suggesting that this situationist assumption is problematic. For example, at 1115a20, Aristotle explicitly discusses the point about characteristics being evinced in certain situations yet not in others:

though some may be cowards in the dangers of war, they are nonetheless liberal and cheerfully confident in the face of a loss of money [which is also a danger but of a different kind]. And someone who is afraid of wanton violence against his children and wife, or of malicious envy or of something of this sort, is not a coward. Nor if a person is confident when he is about to be flogged is he courageous. (NE 1115a20)

\footnotetext{
${ }^{7}$ Vranas (2005) slices his character pie into three slices rather than two by assuming that "character status, [is] understood as status on the good/intermediate/bad scale" (p. 16).
} 
The point here should be especially clear in light of what has been discussed concerning the fourth problem with the situationist use of study 2 and the second problem with the situationist use of study 4. For in both of these cases, the problem with the situationist use of these studies concerned the fact that they simply assumed without argument how the subjects ought to have acted in these situations without taking into consideration their reasons for acting. In the case Aristotle describes at Nicomachean Ethics 1115a20, a situationist might similarly assume without argument that if a man is courageous then he ought to not have fear in any situation, even if someone were committing "violence against his children and wife." But as we discussed before regarding the role of reasons in the helping case from study 2 , Aristotle similarly points out at $1115 \mathrm{a} 20$ that when a man considers the unfortunate situation of someone commiting "wanton violence against his children and wife," he has good reason to be afraid and that this does not imply that he is a coward. On the Aristotelian view friendliness and courage are not brute dispositions that are blind to reasons and independent of situations, as situationists often suppose, but are rather characteristics that are guided by reason and relevant to the particulars of the situation at hand. A soldier with courage is not skilled in the way that he is because he is blind to the particulars of situational contexts, but rather "is skilled in action, at least - for he is someone concerned with ultimate particular things" (NE 1146a5) and "does what is noblest given the circumstances, just as a good general makes use, with the greatest military skill, of the army he has and a shoemaker makes the most beautiful shoe out of the leather given bim. It holds in the same manner with all the other experts as well" (NE 1101a-10, my emphasis). Staff Sergeant Giunta, who was awarded the Medal of Honor for saving the lives of his fellow soldiers after being ambushed by insurgents in Afghanistan, offers an insightful account of the soldier's developed characteristics in his (2012) memoir Living with honor:

In any firefight, there is an instinctive, knee-jerk reaction that immediately follows the first crack of gunfire. Everyone responds differently, but training and experience helped us deal with the initial shock, to resist the body's natural urge to flee - which sounds like a better idea than it really is, since you're likely to get shot in the back. Instead, we learned to seek out the position from which the shot had been fired, to use our ears and eyes to determine the proximity of the enemies position, and to ascertain whether we were in a reasonably safe place. All of this would happen in a matter of seconds $[\ldots]$ The point is, training informs your response, to the point that whatever fear you might feel is channeled appropriately. (p. 245-246, 127) 
A. M. Croom | Integrative Psychological and Behavioral Science 48 (2014) 18-47

http://dx.doi.org/10.1007/s12124-013-9249-8

So it seems that a continually practiced characteristic helps one tune into the particulars of certain kinds of situations, not blind one to them completely, as situationists suggest. In fact, it has now been well-established through recent empirical work, especially in language (Kuhl, Stevens, Hayashi, Deguchi, Kiritani, \& Iverson, 2006; Kuhl \& Rivera-Gaxiola, 2008; Pons, Lewkowicz, Soto-Faraco, \& Sebastian-Galles, 2009) and music perception (Hannon \& Trehub, 2005; Curtis \& Bharucha, 2009; Hyde, Lerch, Norton, Forgeard, Winner, Evans, \& Schlaug, 2009; Kraus, Skoe, Parbery-Clark, \& Ashley, 2009; Schnupp, Nelken, \& King, 2011), that human sensitivities are indeed capable of development and fine-tuning through experience, a process often referred to in the literature as perceptual learning (see also Croom, 2010; Croom, 2012a; Croom, 2012b). ${ }^{8}$

Contra Doris (1998), then, it is not the case that "Aristotle (1984: 1105a28-bl) insists that for an action to be considered truly virtuous it must be determined by the appropriately developed character of the agent" and that Aristotelians are suggesting we "develop characters that will determine our behavior in ways significantly independent of circumstance" (p. 515, my emphasis). 9 This presentation of Aristotelian moral psychology is quite wrong because it neglects the important role of the intellect in Aristotle's account. ${ }^{10}$ Rather than being determined by character alone, which Doris (1998) and Harman (1999) consider to be brute dispositions, Aristotle instead suggests that virtuous deeds "arise in accord with the virtues [...] first, if he acts knowingly; second, if he acts by choosing and by choosing the actions in question for their own sake; and, third, if he acts while being in a steady and unwavering state" (NE 1105a30). Here we see that Aristotle stresses the role of intellect in at least two of the three conditions necessary for virtuous action, with the second condition regarding choice pertaining to what we discussed in the helping case from study 2 where it was stressed that reasons between alternative choices must be taken into consideration in order to understand which action out of a set of alternatives is best. It is hard to stress enough how Aristotle repeatedly drills this in, for concerning things that are frightening to everyone he says that "the courageous man $[\ldots]$ will fear

8 As Schnupp, Nelken, and King (2011) summarize several of these findings in Auditory Neuroscience: Making Sense of Sound, the "maturation of the central auditory pathways is heavily influenced by sensory experience" and so "perceptual abilities also change with experience" (p. 275, 278).

${ }_{9}^{9}$ Merritt (2000) also misleadingly suggests that "Aristotle requires that genuine virtues be firmly secured in one's own individual constitution, in such a way that one's reliability in making good practical choices depends as little as possible on contingent external factors" (p. 375). This claim is misleading because Aristotle explicitly writes that "“Nonetheless, it [happiness] manifestly requires external goods in addition [...] For it is impossible or not easy for someone without equipment to do what is noble: many things are done through instruments, as it were - through friends, wealth, and political power. Those who are bereft of some of these (for example, good birth, good children, or beauty) disfigure their blessedness [...] Just as we said, then, [happiness] seems to require some such external prosperity in addition" (NE 1099a30-2099b5).

${ }^{10}$ One reviewer kindly pointed out how Aristotle (2010) postulated in the Analytics that scientific understanding is primarily concerned with the theoretically general rather than the empirically particular and that Aristotle considered the term character as one applied to the theoretically general rather than the empirically particular, so that once this point is properly taken into consideration the important role of the intellect in Aristotle's account of moral psychology becomes especially clear. I thank the anonymous reviewer for bringing this point to my attention. 
A. M. Croom | Integrative Psychological and Behavioral Science 48 (2014) 18-47

http://dx.doi.org/10.1007/s12124-013-9249-8

things of this sort, then, but he will endure them in the way that he ought and as reason commands"

(NE 1115b10, my emphasis).

Notice, however, that the third condition for virtuous action stated above mentioned that an agent must act "while being in a steady and unwavering state" (NE 1105a30). It is this third condition that has been singled out by situationists and used in support of their claim that Aristotle is committed to broad-based dispositions. Yet depsite the fact that situationists often rely on this point in assuming that Aristotelian characteristics are "firm and unchangeable" (quoted in Doris, 1998, p. 506), and use this in support of their claim that Aristotle is committed to broad-based dispositions, it should be pointed out that there is an ambiguity in how this third condition can be understood (note also that more recent translations interpret the passage at 1105a30-1105b as "steady and unwavering" rather than "firm and unchangeable"; see Aristotle, 2011). Specifically, to suggest that a characteristic is "steady and unwavering" can be interpreted in at least two ways. First, this claim could be interpreted as a claim of intra-situational stability with respect to relatively specific kinds of situations across time. For example, a Navy SEAL may exhibit a characteristic that is stable within combat situations on consecutive days (e.g., they are not prevented from facing the challenges of combat due to fear), whereas a first-grader may not exhibit a characteristic that is stable within academic situations on consecutive days (e.g., they are prevented from facing the challenges of reading aloud due to fear on some days but not on others). Second, this claim could alternatively be interpreted as a claim of inter-situational stability with respect to relatively different kinds of situations. For example, a Navy SEAL may exhibit a characteristic that is stable within certain situations (e.g., friendliness, when with fellow SEAL mates) but not in other very different situations (e.g., unfriendliness, when with militant enemies). So in suggesting that a virtuous characteristic is "steady and unwavering," we have at least two possible interpretations for what this might consist in for Aristotle (see also Sreenivasan, 2002, p. 49-50). ${ }^{11}$

Doris (1998) and Harman (1999) clearly think that Aristotle is committed to inter-situational stability with respect to relatively different kinds of situations, since they ascribe (A1) to Aristotle and think that Aristotle is committed to the claim that character broadly determines behavior irrespective of context (e.g., Doris, 1998, p. 515). But this interpretation seems quite inconsistent with many claims Aristotle makes, such as at $1115 \mathrm{a} 20$ of Nicomachean Ethics where he discusses how some people may be cowards in the face of war but not in the face of loosing money, which are both dangers. Furthermore, Aristotle claims that the virtues of character must be cultivated (NE 1114a5-10) and that this is the aim of proper education (NE 1104b5-10), a point that Doris (1998) and Harman

11 The situationist's misinterpretation of Aristotle here is further complicated by the fact that situationists have not themselves provided a clear account of situations. For further criticism on the situationist's lack of properly defining what situation are, see Sabini and Silver (2005). 
A. M. Croom | Integrative Psychological and Behavioral Science 48 (2014) 18-47

http://dx.doi.org/10.1007/s12124-013-9249-8

(1999) themselves acknowledge, yet it would remain mysterious why Aristotle would claim this if he also held that characteristics are "firm and unchangeable" (quoted in Doris, 1998, p. 506). Instead, it seems rather clear that characteristics for Aristotle are changeable and capable of cultivation, but that they take time to cultivate since this cultivation of characteristics requires being "continually engaged in the relevant activity" (NE 1114a5-10). Further, Aristotle suggests that this continual engagement must carry on beyond one's youth and throughout life: "it is not sufficient if people when they are young attain the correct rearing and care; rather, once they have reached adulthood, they must also make a practice of these things and be thus habituated" (NE 1179b30-1180a5). But through this accumulation of experience and cultivation of characteristics, one eventually acquires a relevant readiness to act and intra-situational stability with respect to certain relevant kinds of situations across time. For instance, a combat soldier will have acquired experience and combat readiness through repeated training and consecutive deployments (see Giunta, 2012), and so will be expected to remain unwavering in courage on upcoming (intra-situational) deployments, but will not likewise be expected to remain unwavering in friendliness if captured behind (inter-situational) enemy lines.

So yet again, not only is the situationist claim that Aristotelians conceive of characteristics as broadly context-insensitive dispositions unsupported by the text, it also does not cohere with many claims that we actually find Aristotle making in Nicomachean Ethics.

To briefly review: the situationist claimed that Aristotelians are committed to characteristics that are broad rather than narrow, and because the situationist conceived of Aristotelian characteristics as broad-based dispositions that are unqualified and context-insensitive, they assume that Aristotelian characteristics must also be invariant across all situations, as expressed in (A1), and rigidly robust in all situations, as expressed in (A2). Yet by considering Aristotle's actual text, we find that Aristotle does not conceive of characteristics as broad-based dispositions that are unqualified and context-insensitive, and thus does not assume that characteristics must also be invariant across all situations, as expressed in (A1), and rigidly robust in all situations, as expressed in (A2).

The situationist claim that Aristotelians are also committed to (A3) is also partly inaccurate, since the relationship among the characteristics for Aristotle is more complex than the situationist suggests in that for Aristotle some of the virtues (such as the virtues of intellect) presuppose others (such as the virtues of character) but not vice versa (NE 1151a15-20, 1179b25-30; see also Aquinas, 1993, p. 446; Reeve, 2012, p. 131), but we need not pursue the details of the argument here. This is because the only study that situationists have used to argue against (A3) and support (S3) instead was the Hartshorne and May (1928) study conducted on children. But it stands to reason that even an Aristotelian integrity thesis that somewhat differed in detail from (A3) would still not have been undermined by the situationist use of the Hartshorne and May (1928) study, since we have already discussed why the results from studies on the characteristics of children cannot be straightforwardly 
A. M. Croom | Integrative Psychological and Behavioral Science 48 (2014) 18-47

http://dx.doi.org/10.1007/s12124-013-9249-8

carried over to conclusions about the characteristics of adults. Furthermore, we saw that further studies suggested that children behave more consistently than Hartshorne and May (1928) originally concluded (Burton, 1963; Hoffman, 2000; Kochanska \& Aksan, 2006), that significantly higher behavioral consistency was found when error variance was corrected for (Rushton, Chrisjohn, \& Fekken, 1981), and that behavior becomes more closely interrelated as people get older (Blasi, 1980; Sigelman \& Rider, 2009). This is all consistent with what Aristotle has suggested about children especially being lured with varying pleasures "from all sides," and thus especially in need of proper habituation and education (see for instance NE 1119b5-15, 1142a10-15, 1143b10; see also 1103b20$25,1104 \mathrm{~b} 5-10)$. So there is in fact empirical evidence, along with prima facie reasons, to suppose that some interrelation of behavioral characteristics among adults does exist, which is not inconsistent with the supposition of some form of the integrity thesis. Detailed discussion of Aristotle's own integrity thesis, however, must be reserved for another occasion.

Finally, it is important to note that what has not been denied in this section is that Aristotle believed in the stability, robustness, and integrity of virtuous characteristics, but only that situationists have correctly ascribed to Aristotle conceptions about these that are accurately Aristotelian. If Aristotle holds theses regarding the stability, robustness, and integrity of characteristics, they are not plausibly as the situationist has characterized them with the aformentioned (A) theses, and as situationists have discussed them in the literature (see especially Doris, 1998; Harman, 1999; Harman, 2000). Yet in not being comitted to the aformentioned (A) theses as the situationist has characterized them, the Aristotelian need not be automatically comitted to the opposing situationist $(\mathrm{S})$ theses, for as we have seen Aristotle is not committed to these extreme theses either. Unlike the situationist, Aristotle is not thinking in terms of characteristics versus situations, with one or the other being solely determinative of behavior, but rather charts out a more nuanced middle path between these extremes. In this respect, at least, the Aristotelian holds something closer to an interactionist view in moral psychology, although interactionist views themselves vary in their details, making it unwise to place Aristotle too close to any of these camps without qualification. But in suggesting that situations not only influence persons but that persons also influence situations (Bowers, 1973; Wachtel, 1973; Stagner, 1976; Olweus, 1977; Blass, 1991), the interactionist can be seen as supplying "a sort of curative treatment" (NE 1104b15) to situationist moral psychology, since "by leading ourselves far from error, we will arrive at the middle term, which is in fact what those who straightened warp lumber do" (NE 1109b-5). Indeed, a number of psychological researchers have in fact shown that personality variables can predict situation choices and preferences (Snyder and Gangestad, 1982; Gormly, 1983; Emmons, Diener, \& Larsen, 1986; Leary, Wheeler, \& Jenkins, 1986; Feather \& Volkmer, 1988), motivating new work that stresses the importance of viewing behavior as a product 
A. M. Croom | Integrative Psychological and Behavioral Science 48 (2014) 18-47

http://dx.doi.org/10.1007/s12124-013-9249-8

of both personal and situational factors (Blass, 1991, p. 406; see also Bowers, 1973; Eysenck and Eysenck, 1980; Bem, 1983; Blass, 1984a; Endler, 1984; Blass, 1987).

\section{Conclusion}

Briefly, an overview of what we have covered: Section 1 introduced the situationist challenge against Aristotelian moral psychology. In section 2 we reviewed the three theses situationists ascribed to Aristotle, the (A1) stability, (A2) robustness, and (A3) evaluative consistency or integrity theses, as well as the three theses situationists claimed to hold themselves, the (S1) instability, (S2) impotence, and (S3) evaluative inconsistency or fragmentation of character theses. In sections 3, 4, 5, and 6 we reviewed the details and results of the studies conducted by Hartshorne and May (1928), Darley and Batson (1973), Isen and Levin (1972), and Milgram (1963), respectively, and how the situationist used each of these results against Aristotelians. Section 7 reconsidered the Hartshorne and May (1928) study and presented 3 problems with the situationist use of it against Aristotelians, section 8 reconsidered the Darley and Batson (1973) study and presented 4 problems with the situationist use of it against Aristotelians, section 9 reconsidered the Isen and Levin (1972) study and presented 1 major problem with the situationist use of it against Aristotelians, and section 10 reconsidered the Milgram (1963) study and presented 2 problems with the situationist use of it against Aristotelians. Finally, section 11 looked deeper into Aristotle's own work on moral psychology and argued that situationists have advanced inaccurate characterizations of his account.

In reviewing the 10 points of concern with the situationist use of studies 1-4, sections 7-10 presented 10 problems with the situationist challenge by raising the following points of concern for each study: 3 points of concern regarding their use of study 1 included (i) the fact that it neglects the amount of behavioral consistency that this study does in fact find, (ii) that it focuses primarily on discussing correlations between single measures instead of combinations of exemplars, and in so doing has neglected to discuss correcting for error variance, and (iii) that it misleadingly overgeneralizes the results from a study whose population group consisted of children to enforce subsequent conclusion concerning all human beings. 4 points of concern regarding their use of study 2 included (i) the fact that it neglects the amount of behavioral robustness that this study does in fact find, (ii) that it misleadingly over-generalizes the results from a study whose population group consisted of students to enforce subsequent conclusions concerning all human beings, (iii) that it misleadingly over-generalizes the results from a study whose population group consisted of seminarians to enforce subsequent conclusions concerning all human beings, and (iv) that it simply assumes without argument how subjects ought to have acted without taking into consideration their reasons for acting. 1 major point of concern for study 3 included (i) the fact that this was not a 
A. M. Croom | Integrative Psychological and Behavioral Science 48 (2014) 18-47

http://dx.doi.org/10.1007/s12124-013-9249-8

replicable finding. 2 points of concern for study 4 included (i) the fact that it neglects the amount of behavioral robustness that this study does in fact find, and (ii) that it simply assumes without argument that it was obvious for the subject to have reasonably disobeyed the experimenter before the point at which the learner starts protesting (i.e., at the 300-volt level) irrespective of the subject's reasons for continuing. Taken together, these 10 points raise serious doubts about the strength of the situationist challenge against Aristotelian moral psychology.

Situationists give up on virtuous character because their demands of character are too extreme, rather than the right amount. They often incorrectly ascribe to Aristotelians the extreme view that characteristics rather than situations determine human behavior, and then argue against this by endorsing the equally extreme opposing view that situations rather than characteristics determine human behavior. But throughout the course of this article we have seen that the empirical data is not adequately explained by supposing that either characteristics alone or situations alone determine human behavior, and that Aristotle never endorsed such extreme views himself, as situationists often suggest. The situationist's own account, as well as their explication of the Aristotelian account, has consisted of uncritical generalizations that are not nuanced enough to account for much empirical data from the social sciences, as well as textual evidence from Aristotelian philosophy. It remains to be fully argued, but perhaps the experienced eye of Aristotle was more nuanced, and a bit better at hitting the right mark, than many today often give him credit for. ${ }^{12}$

\section{Acknowledgements}

I would first and foremost like to give warm thanks to Marty Seligman, Paul Rozin, and the Positive Psychology Center at the University of Pennsylvania for generously funding and supporting the research for this article. I would also like to express my gratitude to Geoff Goodwin from the Social Psychology Lab at the University of Pennsylvania and Paul Bloom from the Mind and Development Lab at Yale University for the valuable research experience I acquired from their labs. My sincere thanks also goes out to Mark Sheskin, Amber Cazzell, Rebecca Lange, Jared Piazza, Justin Landy, Konika Banerjee, Thalia Goldstein, Lily Guillot, and Christina Starmans for many fruitful discussions on moral character and experiments from social psychology. I am also very thankful for the thoughtful comments and valuable suggestions for this article that I received from Paul Rozin, Sergio Salvatore, and two anonymous reviewers at Integrative Psychological and Behavioral Science. Finally, I am extremely grateful for the excellent training, education, and inspiration that I received from my mentors Master Charles Robert from Shaolin Kung Fu (Brea, California) and Sergeant Timothy

\footnotetext{
${ }^{12}$ An earlier draft of this paper was awarded the 2012-2013 Positive Studies Prize for best essay in positive
} psychology from the Positive Psychology Center at the University of Pennsylvania. 
A. M. Croom | Integrative Psychological and Behavioral Science 48 (2014) 18-47

http://dx.doi.org/10.1007/s12124-013-9249-8

Phillips from the United States Air Force (San Antonio, Texas) and I would like to honor these two influential people in my life by dedicating the present article to them.

\section{References}

Aquinas, T. (1993). Commentary on Aristotle's Nicomachean Ethics, C. Litzinger (trans.). Notre Dame: Dumb Ox Books.

Aristotle. (1963). Categories and de interpretatione, J. Ackrill (trans.). Oxford: Oxford University Press.

Aristotle. (1998). Politics, C. Reeve (trans.). Indianapolis: Hackett.

Aristotle. (2000). Prior and posterior analytics, W. D. Ross (trans.). Oxford: Oxford University Press.

Aristotle. (2011). Nicomachean ethics, R. C. Barlett \& S. D. Collins (trans.). Chicago: University of Chicago Press.

Athanassoulis, N. (2000). A response to Harman: Virtue ethics and character traits. Proceedings of the Aristotelian Society, 100, 215-221. http://dx.doi.org/10.1111/j.0066-7372.2003.00012.x.

Bem, D. (1983). Toward a response style theory of persons in situations. In M. Page (ed.), Nebraska symposium on motivation, 1982: Personality - Current theory and research (pp. 201-231). Lincoln: University of Nebraska Press.

Blasi, A. (1980). Bridging moral cognition and moral action: A critical review of the literature. Psychological Bulletin, 88, 1-45. http://dx.doi.org/10.1037/0033-2909.88.1.1.

Blass, T. (1984). Interactionism. In R. Corsini (ed.), Encyclopedia of psychology, volume 2 (pp. 234-235). New York: Wiley.

Blass, T. (1987). Interactionism. In R. Corsini (ed.), Concise encyclopedia of psychology (pp. 605-606). New York: Wiley.

Blass, T. (1991). Understanding behavior in the Milgram obedience experiment: The role of personality, situations, and their interactions. Journal of Personality and Social Psychology, 60, 398-413. http://dx.doi.org/10.1037/0022-3514.60.3.398.

Blevins, G., \& Murphy, T. (1974). Feeling good and helping: Further phonebooth findings. Psychological Reports, 34, 326. http://dx.doi.org/10.2466/pr0.1974.34.1.326.

Bowers, K. (1973). Situationism in psychology: An analysis and a critique. Psychological Review, 80, $307-$ 336. http://dx.doi.org/10.1037/h0035592.

Burley, P., \& McGuinness, J. (1977). Effects of social intelligence on the Milgram paradigm. Psychological Reports, 40, 767-770. http://dx.doi.org/10.2466/pr0.1977.40.3.767.

Burton, R. (1963). Generality of honesty reconsidered. Psychological Review, 70, 481-499. http://dx.doi.org/10.1037/h0047594. 
A. M. Croom | Integrative Psychological and Behavioral Science 48 (2014) 18-47

http://dx.doi.org/10.1007/s12124-013-9249-8

Croom, A. (2010). Thick concepts, non-cognitivism, and Wittgenstein's rule-following considerations. South African Journal of Philosophy, 29, 209-232. http://dx.doi.org/10.4314/sajpem.v29i3.59143.

Croom, A. (2012a). Aesthetic concepts, perceptual learning, and linguistic enculturation: Considerations from Wittgenstein, language, and music. Integrative Psychological and Behavioral Science, 46, 90-117. http://dx.doi.org/10.1007/s12124-011-9184-5.

Croom, A. (2012b). Music, neuroscience, and the psychology of well-being: A précis. Frontiers in Psychology, 2, 393. http://dx.doi.org/10.3389/fpsyg.2011.00393.

Curtis, M., \& Bharucha, J. (2009). Memory and musical expectation for tones in cultural contexts. Music Perception, 26, 365-375. http://dx.doi.org/10.1525/MP.2009.26.4.365.

Darley, J., \& Batson, C. (1973). "From Jerusalem to Jericho": A study of situational and dispositional variables in helping behavior. Journal of Personality and Social Psychology, 27, 100-108.

http://dx.doi.org/10.1037/h0034449.

Doris, J. (1998). Persons, situations, and virtue ethics. Nous, 32, 504-530. http://dx.doi.org/10.1111/0029-4624.00136.

Elms, A. (1972). Social psychology and social relevance. Boston: Little, Brown.

Elms, A., \& Milgram, S. (1966). Personality characteristics associated with obedience and defiance toward authoritative command. Journal of Experimental Research in Personality, 1, 282-289.

Emmons, R., Diener, E., \& Larsen, R. (1986). Choice and avoidance of everyday situations and affect congruence: Two models of reciprocal interactionism. Journal of Personality and Social Psychology, 51, 815-826. http://dx.doi.org/10.1037/0022-3514.51.4.815.

Endler, N. (1984). Interactionism. In N. Endler \& J. McV Hunt (eds.), Personality and the behavioral disorders, volume 1 (pp. 183-217). New York: Wiley.

Eng, J. (2012). Homeless numbers down, but risks rise. NBC News. http://usnews.nbcnews.com/_news/2012/01/18/10177017-homeless-numbers-down-butrisks-rise?lite.

Eysenck, H. (1939). Primary mental abilities. British Journal of Educational Psychology, 9, 270-275. http://dx.doi.org/10.1111/j.2044-8279.1939.tb03214.x.

Eysenck, M., \& Eysenck, H. (1980). Mischel and the concept of personality. British Journal of Psychology, 71, 191-204. http://dx.doi.org/10.1111/j.2044-8295.1980.tb01737.x.

Feather, N., \& Volkmer, R. (1988). Preference for situations involving effort, time pressure, and feedback in relation to Type A behavior, locus of control, and test anxiety. Journal of Personality and Social Psychology, 55, 266-271. http://dx.doi.org/10.1037/0022-3514.55.2.266. 
A. M. Croom | Integrative Psychological and Behavioral Science 48 (2014) 18-47

http://dx.doi.org/10.1007/s12124-013-9249-8

Fleeson, W., \& Gallagher, P. (2009). The implications of Big Five standing for the distribution of trait manifestation in behavior: Fifteen experience-sampling studies and a meta-analysis. Journal of Personality and Social Psychology, 97, 1097-1114. http://dx.doi.org/10.1037/a0016786.

Giunta, S. (2012). Living with honor: A memoir of Medal of Honor recipient Staff Sergeant Salvatore A. Giunta. New York: Simon \& Schuster.

Gormly, J. (1983). Predicting behavior from personality trait scores. Personality and Social Psychology Bulletin, 9, 267-270. http://dx.doi.org/10.1177/0146167283092011.

Hannon, E., \& Trehub, S. (2005). Tuning in to musical rhythms: infants learn more readily than adults. Proceedings of the National Academy of Sciences of the United States of America, 102, 12639-12643. http://dx.doi.org/10.1073/pnas.0504254102.

Harman, G. (1999). Moral philosophy meets social psychology: Virtue ethics and the fundamental attribution error. Proceedings of the Aristotelian Society, 99, 315-331. http://www.jstor.org/stable/4545312.

Harman, G. (2000). The nonexistence of character traits. Proceedings of the Aristotelian Society, 100, 223226. http://www.jstor.org/stable/4545327.

Hartshorne, H., \& May, M. (1928). Studies in the nature of character, volume 1: Studies in deceit. New York: MacMillan.

Hartshorne, H., May, M., \& Maller, J. (1929). Studies in the nature of character, volume 2: Studies in selfcontrol. New York: MacMillan.

Haas, K. (1966). Obedience: Submission to destructive orders as related to hostility. Psychological Reports, 19, 32-34. http://dx.doi.org/10.2466/pr0.1966.19.1.32.

Heraclitus. (2001). Fragments, B. Haxton (trans.). New York: Penguin Books.

Hoffman, M. (2000). Empatby and moral development: Implications for caring and justice. Cambridge: Cambridge University Press.

Holland, C. (1967). Sources of variance in the experimental investigation of behavioral obedience. Dissertation Abstracts International, 29, 2802A. (University Microfilms No. 69-2146)

Hyde, K., Lerch, J., Norton, A., Forgeard, M., Winner, E., Evans, A., \& Schlaug, G. (2009). Musical training shapes structural brain development. Journal of Neuroscience, 29, 3019-3025. http://dx.doi.org/10.1523/JNEUROSCI.5118-08.2009.

Isen, A., \& Levin, P. (1972). Effect of felling good on helping: Cookies and kindness. Journal of Personality and Social Psychology, 21, 384-388. http://dx.doi.org/10.1037/h0032317.

Kochanska, G. \& Aksan, N. (2006). Children's conscience and self-regulation. Journal of Personality, 74, 1587-1617. http://dx.doi.org/10.1111/j.1467-6494.2006.00421.x. 
A. M. Croom | Integrative Psychological and Behavioral Science 48 (2014) 18-47

http://dx.doi.org/10.1007/s12124-013-9249-8

Kraus, N., Skoe, E., Parbery-Clark, A., \& Ashley, R. (2009). Experience-induced malleability in neural encoding of pitch, timbre, and timing. Annals of the New York. Academy of Sciences, 1169, 543-557. http://dx.doi.org/10.1111/j.1749-6632.2009.04549.x.

Kraut, R. (2012). Aristotle's ethics. Stanford Encyclopedia of Philosophy. http://plato.stanford.edu/archives/win2012/entries/aristotle-ethics/.

Kuhl, P., \& Rivera-Gaxiola, M. (2008). Neural substrates of language acquisition. Annual Review of Neuroscience, 31, 511-534. http://dx.doi.org/10.1146/annurev.neuro.30.051606.094321.

Kuhl, P., Stevens, E., Hayashi, A., Deguchi, T., Kiritani, S., \& Iverson, P. (2006). Infants shown a facilitation effect for native language phonetic perception between 6 and 12 months. Developmental Science, 9, F13-F21. http://dx.doi.org/10.1111/j.1467-7687.2006.00468.x.

Leary, M., Wheeler, D., \& Jenkins, T. (1986). Aspects of identity and behavioral preference: Studies of occupational and recreational choice. Social Psychology Quarterly, 49, 11-18. http://dx.doi.org/10.2307/2786853.

Lerner, B. (2011). Benevolence. In K. Ryan, B. Lerner, K. Bohlin, O. Nakayama, S. Mizuno \& K. Horiuchi (eds.), Happiness and virtue beyond east and west: Towards a new global responsibility (pp. 95103). Tuttle: Tokyo.

Merritt, M. (2000). Virtue ethics and situationist personality psychology. Ethical Theory and Moral Practice, 3, 365-383. http://dx.doi.org/10.1023/A:1009926720584.

Merritt, M. (2009). Aristotelian virtue and the interpersonal aspect of ethical character. Journal of Moral Philosophy, 6, 23-49. http://dx.doi.org/10.1163/174552409X365919.

Milgram, S. (1963). Behavioral study of obedience. Journal of Abnormal and Social Psychology, 67, 371378. http://dx.doi.org/10.1037/h0040525.

Milgram, S. (1974). Obedience to authority: An experimental view. New York: Harper \& Row.

Miller, C. (2003). Social psychology and virtue ethics. The Journal of Ethics, 7, 365-392. http://dx.doi.org/10.1023/A:1026136703565.

Miller, F. (1975). An experimental study of obedience to authorities of varying legitimacy. Ph.D. dissertation, Harvard University.

Olweus, D. (1977). A critical analysis of the "modern" interactionist position. In D. Magnusson \& N. Endler (eds.), Personality at the crossroads: Current issues in interactional psychology (pp. 221-233). Hillsdale: Erlbaum.

Pons, E., Lewkowicz, D., Soto-Faraco, S., \& Sebastian-Galles, N. (2009). Narrowing of intersensory speech perception in infancy. Proceedings of the National Academy of Sciences of the United States of America, 106, 10598-10602. http://dx.doi.org/10.1073/pnas.0904134106.

Prinz, J. (2009). The normativity challenge: Cultural psychology provides the real threat to virtue ethics. The Journal of Ethics, 13, 117-144. http://dx.doi.org/10.1007/s10892-009-9053-3. 
A. M. Croom | Integrative Psychological and Behavioral Science 48 (2014) 18-47

http://dx.doi.org/10.1007/s12124-013-9249-8

Prinz, J. (2008). Is morality innate? In W. Sinnott-Armstrong (ed.), Moral psychology: The evolution of morality: Adaptations and innateness (pp. 367-406). Cambridge: MIT Press.

Reeve, C. (2012). Action, contemplation, and happiness: An essay on Aristotle. Cambridge: Harvard University Press.

Rotter, J. (1990). Internal versus external control of reinforcement: A case history of a variable. American Psychologist, 45, 489-493. http://dx.doi.org/10.1037/0003-066X.45.4.489.

Rushton, J., Chrisjohn, R., \& Fekken, G. (1981). The altruistic personality and the self-report altruism scale. Personality and Individual Differences, 2, 293-302.

Sabini, J., \& Silver, M. (2005). Lack of character? Situationism reconsidered. Ethics, 115, 535-562. http://www.jstor.org/stable/10.1086/428459.

Schmitt, D., Realo, A., Voracek, M., \& Allik, J. (2008). Why can't a man be more like a woman? Sex differences in Big Five personality traits across 55 cultures. Journal of Personality and Social Psychology, 94, 168-182. http://dx.doi.org/10.1037/0022-3514.94.1.168.

Schnupp, J., Nelken, I., \& King, A. (2011). Auditory neuroscience: Making sense of sound. Cambridge: MIT Press.

Shalala, S. (1974). A study of various communication settings which produce obedience by subordinates to unlawful superior orders. Dissertation Abstracts International, 36, 979. (University Microfilms No. 75-17,675)

Sigelman, C., \& Rider, E. (2009). Life-span buman development. Belmont: Wadsworth.

Snyder, M., \& Gangestad, S. (1982). Choosing social situations: Two investigations of self-monitoring processes. Journal of Personality and Social Psychology, 43, 123-135. http://dx.doi.org/10.1037/00223514.43.1.123.

Spearman, C. (1910). Correlation calculated from faculty data. British Journal of Psychology, 3, 271-295.

Sreenivasan, G. (2002). Errors about errors: Virtue theory and trait attribution. Mind, 111, 47-68. http://dx.doi.org/10.1093/mind/111.441.47.

Stagner, R. (1976). Traits are relevant: Theoretical analysis and empirical evidence. In N. Endler \& D. Magnusson (eds.), Interactional psychology and personality (pp. 109-124). New York: Hemisphere.

Trump, D. (2007). Wesley Autrey: The Time 100. Time Magazine. http://www.time.com/time/specials/2007/time100/article/0,28804,1595326_1615754_161574 6,00.html.

Vranas, P. (2005). The indeterminacy paradox: Character evaluations and human psychology. Nous, 39, 1-42. http://dx.doi.org/10.1111/j.0029-4624.2005.00492.x.

Wachtel, P. (1973). Psychodynamics, behavior therapy, and the implacable experimenter: An inquiry into the consistency of personality. Journal of Abnormal Psychology, 82, 324-334.

http://dx.doi.org/10.1037/h0035132. 
A. M. Croom | Integrative Psychological and Behavioral Science 48 (2014) 18-47

http://dx.doi.org/10.1007/s12124-013-9249-8

Westerhoff, N. (2008). Set in our ways. Scientific American Mind, 19, 44-49.

Weyant, J., \& Clark, R. (1976). Dimes and helping: The other side of the coin. Personality and Social Psychology Journal, 3, 107-110. http://dx.doi.org/10.1177/014616727600300119.

Wills, A., Lavric, A., Croft, G., \& Hodgson, T. (2007). Predictive learning, prediction errors, and attention: Evidence from event-related potentials and eye tracking. Journal of Cognitive Neuroscience, 19, 843-854. http://dx.doi.org/10.1162/jocn.2007.19.5.843.

Witte, P. (2012). The state of homelessness in American 2012. Homelessness Research Institute. http://msnbcmedia.msn.com/i/MSNBC/Sections/NEWS/z-pdf-archive/homeless.pdf.

Zahn-Waxler, C., \& Radke-Yarrow, M. (1990). The origins of empathic concern. Motivation and Emotion, 14, 107-130. http://dx.doi.org/10.1007/BF00991639.

Zahn-Waxler, C., Radke-Yarrow, M., \& King, R. (1979). Child rearing and children's prosocial initiations toward victims of distress. Child Development, 50, 319-330.

http://www.jstor.org/stable/1129406. 